\title{
Misguided Organizational Change Initiatives And How It Promotes A Destructive Work Environment
}

\author{
Orlando Rivero, D.B.A., Carlos Albizu University, USA
}

\begin{abstract}
The purpose of this paper is to review recent trends as they relate to organizational change and how these trends have affected the overall work environment. Over the years, United States corporations have successfully done well financially. However, due to downsizing initiatives and the outsourcing of products and services to other countries in order to stay competitive, United States firms have been forced to do more, but with less resources. Bullying in the workplace has been around for several years; however, employees are being pushed to do more for less with unrealistic work expectations. Workforce bullying has become an epidemic of mass portions, which has led to dysfunctional organizations and inappropriate behavior among employers/employees. At the end, recommendations will be made to promote positive work environments while contributing to organizational change initiatives.
\end{abstract}

Keywords: Public Administration; Public Service; Management; Leadership Organizational Development; Learning Organizations; Organizational Learning; Organizational Development Interventions; Organizational Change; Workforce Bullying; Policies And Procedures; Evaluation Of Human Resources; Structure And Design; Training And Development; Human Resources; Communication; And Leadership

\section{INTRODUCTION}

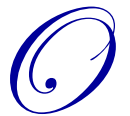

rganizational change continues to be arguably the solution to remain competitive for most United States mid/large organizations. For several years, studies have suggested that swift organizational change initiatives are needed to stay ahead of organizational competitors. Throughout the years, organizations have been forced to do more with less due to scarce resources. In some cases, employees are pushed to perform at peak levels with unrealistic expectations, which has resulted in a counterproductive work environment. The causes and effects of swift organizational changes have had an impact on the overall job performance of employees. Consequently, misguided organizational change has promoted the mistreatment of employees, which has had a negative effect on the overall work productivity.

\section{ORGANIZATIONAL CHANGE IN THE WORKPLACE}

Organizations will continue to improve productivity in an effort to remain competitive in the global economy. Organizations are challenged daily and are regularly improving their services in an effort to stay ahead of their competitors. "....more and more organizations will be pushed to reduce costs, improve quality of products and services, locate new opportunities for growth and increase productivity" (Kotter, 1996, p.3).

Consequently, transformation in an organization becomes unavoidable. Transformation to the organization, which is better known as organizational change, will have a drastic effect over the business subsystems and the organizational culture (French, 1999, p.234). As organizational change begins to evolve in the workplace, employees are uncertain of the organization's future. This could be a very stressful moment for the employees due to their resistance to change and doubtful future with the organization. A study suggested that 288 organizations from 51 countries, revealed reasons why employees may resist change due to corporate historical failures, and the organizational culture issues (Lorenzo, 2000). 
Moreover, as listed in Table 1 and Figure 1, United States patents filed from 2000 through 2011 have nearly doubled. Just within the United States alone, the filing of patents increased from, 315,015 in the year 2000 to 535,188 in 2011. According to a recent study conducted by Kotter (2008), "it is estimated that 70 percent of needed change either fails to be launched or completed" (p.12). At the end, investors are hurt, as well as employees, who are misguided to the outer limits of unreachable goals and objectives due to scarce resources.

Table 1: US Total US Patent Applications

\begin{tabular}{|c|c|}
\hline Year of Application & Total Patent Applications \\
\hline 2000 & 315,015 \\
\hline 2001 & 345,732 \\
\hline 2002 & 356,493 \\
\hline 2003 & 366,043 \\
\hline 2004 & 382,139 \\
\hline 2005 & 417,508 \\
\hline 2006 & 452,633 \\
\hline 2007 & 484,955 \\
\hline 2008 & 485,312 \\
\hline 2009 & 482,871 \\
\hline 2010 & 520,277 \\
\hline
\end{tabular}

(Source: U.S. Patent and Trademark Office, 2012)

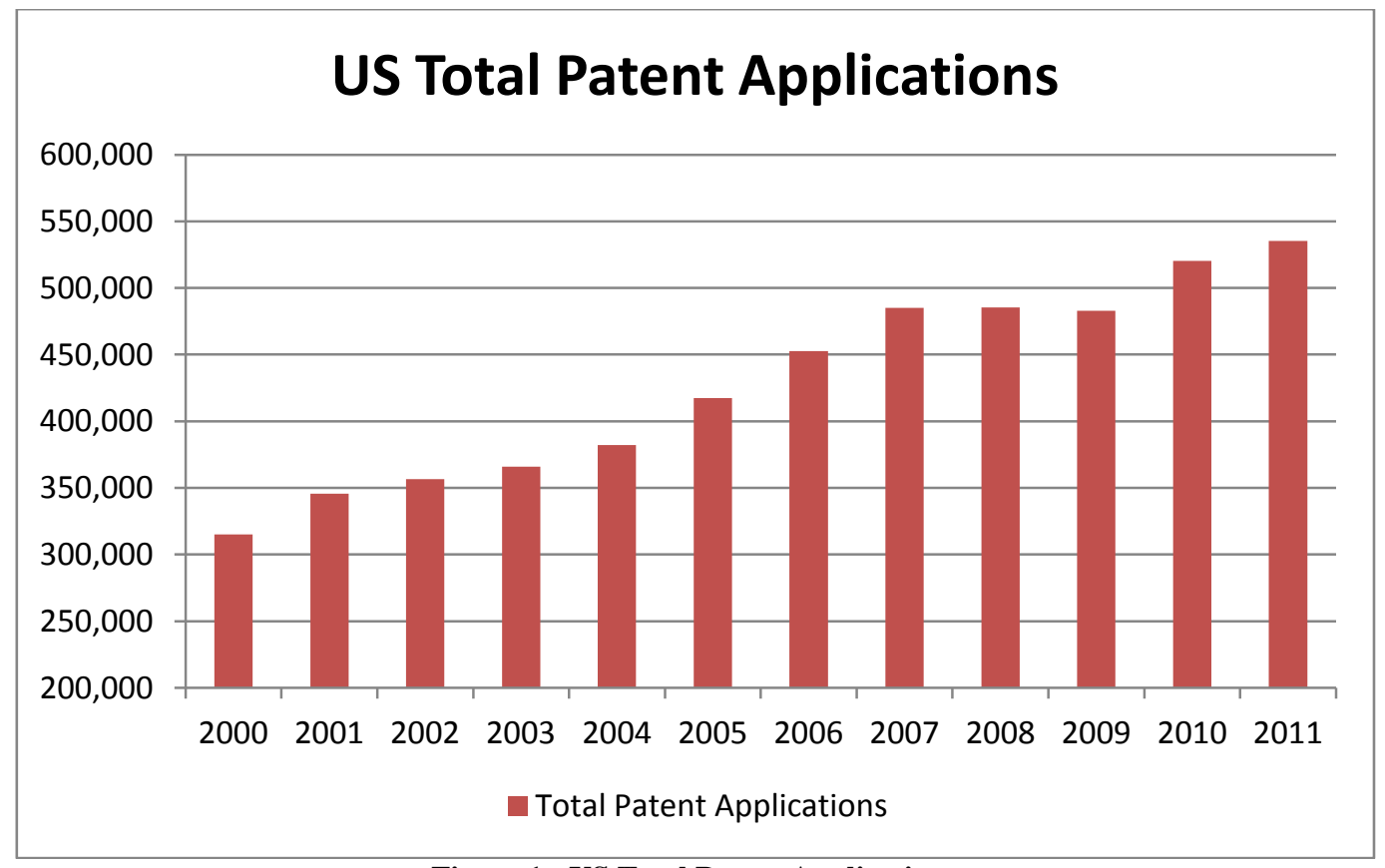

Figure 1: US Total Patent Applications

(Source: U.S. Patent and Trademark Office, 2012)

\section{WORKPLACE BULLYING - CAUSES AND EFFECTS}

As a result of global competition and swift organizational change initiatives, pressure has been placed on American managers to produce more, but with fewer resources. Throughout the years, the majority of layoffs were middle managers who worked alongside of line workers. In so doing, other managers who remained behind were forced to do more with fewer resources, which made it difficult to accomplish day-to-day objectives. To deal with staffing shortage issues, managers developed a "siege mentality" behavior. Horstein (1996) further points out that the "siege mentality" exists when managers are forced to micromanage subordinates in order to keep on top of dayto-day job functions. Unfortunately, this kind of behavior ignites a surge of brutality that includes the mistreatment of others in the workplace by supervisory staff members. Sadly, workforce bullying is driven by for-profit 
objectives to maximize productivity due to lowered labor costs abroad, which has promoted fierce competition (The New York Times, 1996). Additionally, Namie \& Namie (2000) describe a bully in the workplace as a person of authority within an organization who deliberately, hurts and mistreats employees. The study further suggested that bullying in the workplace is destructive to the work environment. According to Hodson, Roscigno, and Lopez, (2006), out of 148 organizations worldwide, $49 \%$ of workplace bullying is a commonly accepted practice (p. 391). Additionally, according to a study conducted by the Workplace Bullying Institute, of which $80 \%$ (1,000 sample size) of the respondents were women, many experienced some sort of work harassment in the workplace. The following are horrific findings that suggest that most respondents incurred the following health aliments as a result of related work harassment. They are as follows: Anxiety (76\%), Loss of concentration (71\%), Disrupted sleep (71\%), Hyper vigilance symptoms (60\%), and Stress headaches (55\%) (Namie, 2012).

Most alarming, as listed in Figure 2, a recent study suggested that in a given time period (a 5-12 month period in an organizational work setting), $13 \%$ of workers are bullied in some sort of fashion by a supervisor/manager (Namie, 2007).

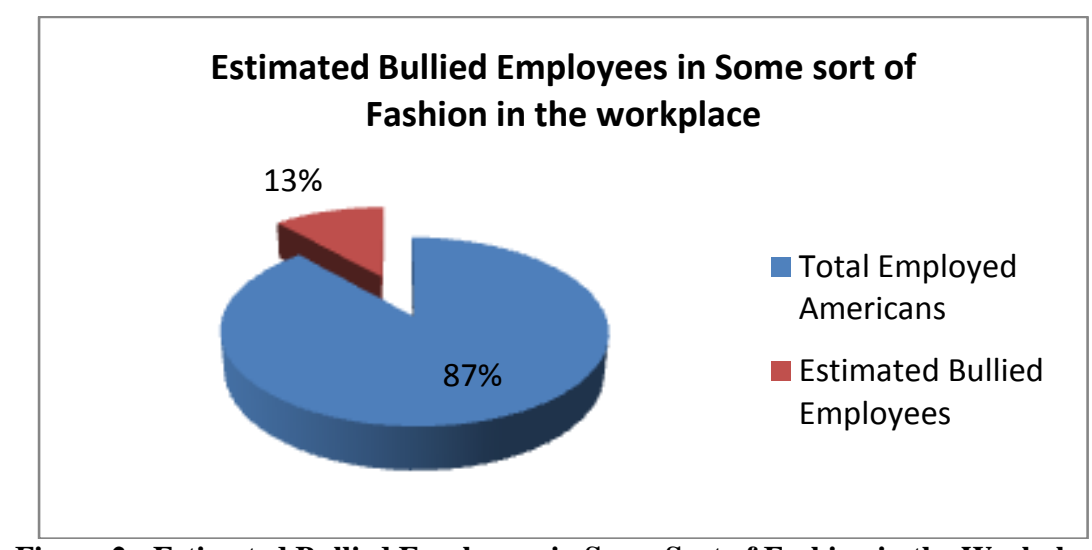

Figure 2: Estimated Bullied Employees in Some Sort of Fashion in the Workplace (Source: Namie, 2007)

However, as indicated in Figure 3, Namie further suggests that the number of victims who are bullied in the workplace increases to $37 \%$ throughout the lifetime of a worker employed for that particular organization.

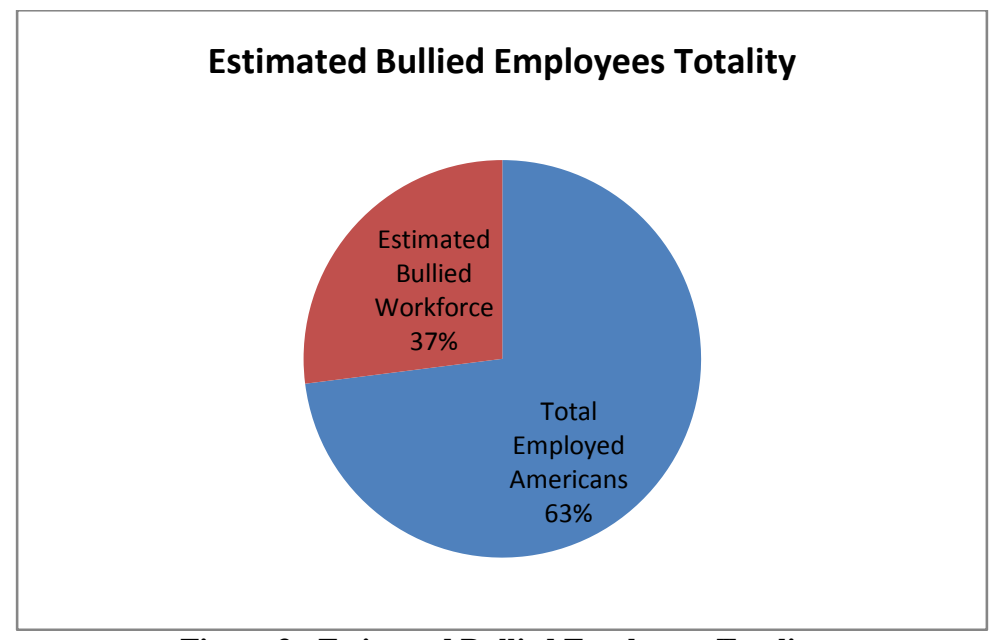

Figure 3: Estimated Bullied Employees Totality (Source: Namie 2007)

Unfortunately, the percentages translate into millions of workers who are being mistreated in some sort of way. According to the Bureau of Labor Statistics, out of 146 million Americans who were employed in July 2007, it 
is estimated that 54 million Americans have been bullied in the workplace. (Namie, 2007). Most importantly, it is estimated that workplace bullying (employer/employee) costs Fortune 500 firms approximately, $\$ 24$ million in lost wages due to absenteeism and add additional \$1.6 million in ligation costs (Namie, 2000).

\section{CONCLUSION}

Organizational change initiatives will continue to be a focal point of existing organizations in an effort to remain competitive. Although fierce competition among United States Corporations will never be diminished, work expectations should be well balanced and articulated to all staff members. By not doing so, this creates a false sense of urgency that promotes a siege of workplace bullying that could lead to the overall destruction of the organization.

Promoting false promises will lead to undeliverable expectations. It is important that work expectations are aligned with the organization's strategic plan. Overall, most mid/large organizations have made some improvements, but there is still more work to be done. This writer does offer several recommendations to promote a positive work environment during organizational change initiatives. They are as follows (Rivero, 2011):

1. Establish an open dialogue with staff to reconnect. This promotes a positive work environment among all staff members.

2. Remind managers of the importance of establishing work synergy among staff members. At times, emotionally driven individuals lose touch with the humanistic approach.

3. Supervisory staff/managers should promote a high sense of energy. Do not act anxious or angry, but act calmly during difficult times.

4. Embrace organizational threats as an opportunity to improve work processes.

5. Neutralize all relentless people who promote a negative work environment. Explain to them that they are part of the organization and their cooperation is needed during the transition phase.

\section{AUTHOR INFORMATION}

Orlando Rivero is the Director, Business Department (School of Business) at Carlos Albizu University. Dr. Rivero serves as the chief learning officer directing the administration, policies, integrity, program, and personnel of the instructional programs. He additionally provides leadership in areas of professional development for interdisciplinary faculty to ensure quality of academic programs. Dr. Rivero provides leadership and direction for all academically-related issues, including program and accreditation as well as instructional and curricular initiatives, to meet the changing needs of the community. Dr. Rivero is the vice-president of JDT Management Consultants in Clearwater, Florida, specializing in management, organization, strategy, international business, human resources, organizational development, and educational administration.

Prior to embarking into academia, Dr. Rivero also served in various leadership roles for 20 years with the local government. His experience within Miami-Dade County includes work within the following roles and departments: Administrator of Operations, Miami-Dade Police Department - Animal Services Unit, Budget Analyst, Miami Dade Corrections \& Rehabilitation Department, and Affirmative Action Administrator, Department of Business Development. During his tenure with Miami-Dade County, he was also the recipient of the 2004 National Association of Counties (NACO) Achievement Award for the implementation of several community-driven programs in Miami-Dade County, Florida.

He earned his Doctoral degree in Business from Argosy University and completed his Master of Public Administration degree at Nova Southeastern University. Dr. Rivero's primary research focus is on public Administration, leadership, management, and effective communication. E-mail: orivero01@ yahoo.com

\section{REFERENCES}

1. $\quad$ French, W. L. (1999). Organization development (6th ed.). Upper Saddle, NJ: Prentice-Hall.

2. Hornstein, H. A. (1996). Brutal bosses and their prey: How to identify and overcome abuse in the workplace. New York: Riverhead Books. 
3. Hodson, R., Roscigno, V. J., \& Lopez, S. H. (2006). Chaos and the abuse of power: Workplace bullying in organizational and interactional context. Work and Occupations, 33(4), 382-416.

4. Kotter, J. P. (1996). Leading Change. Boston, MA: Harvard Business School Press.

5. $\quad$ Kotter, J. P. (2008). A Sense of Urgency. Boston, MA: Harvard Business School Press.

6. Lorenzo, J.D. (2000) "Barreras en los procesos de cambio en las organizaciones: studio de un caso", Paper presented at the X Congreso Nacional de ACEDE, Oviedo (Spain).

7. Namie, G., \& Namie, R. (2000). The bully at work: What you can do to stop the hurt and reclaim your dignity on the job. Naperville, IL: Sourcebooks.

8. Namie, G. (2007). The Workplace Bullying Institute 2007 U.S. Workplace Bullying Survey. Retrieved September 16, 2007, from http://bullyinginstitute.org/wbi-zogby2.html

9. Namie, G. (2012). The WBI Website 2012 instant poll D - impact of workplace bullying on individuals' health. Retrieved January 7, 2013 from http://www.workplacebullying.org/multi/pdf/WBI-2012-IP-D.pdf

10. Rivero, O. (2011, October 3). False Promises \& Dreams, Grantham University. Retrieved January 7, 2013, from http://blog.grantham.edu/blog/?Author=Orlando\%20Rivero

11. The New York Times, The Downsizing o America 55 (1995) (reporting results of a December 1995 public opinion survey concerning economic insecurity and job market.

12. U.S. Patents and Trademark Office (2012). U.S. patent statistics chart calendar years 1963-2011. Retrieved DATE, from http://www.uspto.gov/web/offices/ac/ido/oeip/taf/us stat.htm 
NOTES 